\title{
Matemática do dia a dia: construindo conhecimentos a partir do cotidiano dos alunos EJA
}

\author{
Msc. Mirela Stefânia Pacheco mirelastefania@terra.com.br
}

Dra. Lucia Maria Martins Giraffa - Pesquisadora do Mestrado em Educação em Ciências e Matemática da PUCRS giraffa@pucrs.br

Resumo: O presente artigo apresenta o resultado da investigação realizada com duas turmas de VI fase da EJA (Educação de Jovens e Adultos), do período noturno, de uma escola municipal do município de Novo Hamburgo-RS. O objetivo deste trabalho foi diversificar o ensino de conteúdos de Geometria Plana, utilizando um software de simulação para construção de plantas arquitetônicas e um programa de editoração de imagens. Esta proposta metodológica buscou incluir elementos que auxiliassem na Inclusão Digital destes alunos e diminuir a reprovação e evasão escolar causada pelas dificuldades no estudo da Matemática. Os resultados demonstraram que ao associarmos os exercícios e atividades ao cotidiano destes alunos, obtiveram-se indicadores de melhoria da sua aprendizagem no que tange aos conteúdos de geometria e incremento positivo na sua auto-estima.

Palavras-chave: Geometria Plana. Inclusão Digital. Software Educacional. Educação de Jovens e Adultos.

\section{Building Math Geometry concepts from daily activities; a case study with EJA students}

\begin{abstract}
This paper presents the results of a research with adults students from a Night Elementary School at Novo Hamburgo (Brazil). The methodological approach was designed to developed computer skills and Geometry concepts using a set of activities based on problems related to everyday students' work. The results showed us this methodology help students to increase their self-esteem and decrease students reprobation related to Math discipline.
\end{abstract}

Keywords: Geometry. Digital Inclusion. Educational Software. Adult Education.

\section{1-Introdução}

O público da EJA (Educação de Jovens e Adultos) é diversificado e no corpo discente encontram-se adolescentes, adultos jovens, adultos maduros e idosos. Estes alunos foram excluídos da educação escolarizada formal por diversas razões, decorrentes, em sua maioria, de um tipo de sistema socioeconômico que os impediu de realizar sua formação, no Ensino Fundamental, na época prevista pelo MEC, ou seja, durante a infância e o início da adolescência. Como esta clientela possui uma história de vida com expressiva e diferenciada bagagem cultural, é necessário que este contexto prévio seja valorizado. Importante salientar que este público possui conhecimentos prévios (conceitos, proposições, princípios, fatos, imagens, símbolos) a respeito dos 
conteúdos matemáticos que utilizam diariamente na sua vida profissional ou no orçamento doméstico.

Acredita-se que os conteúdos ensinados na disciplina de Matemática não são percebidos por estes alunos como elementos integrantes da solução de problemas do seu cotidiano. Como conseqüência desta dissociação, aprender Matemática é algo penoso e complicado. Quando, na realidade, é justamente o oposto, a Matemática faz parte do seu dia a dia. Especialmente, daqueles que trabalham na construção civil e no comércio, como é o caso da maioria dos alunos EJA, sujeitos desta pesquisa.

Desta forma, os métodos de ensino que privilegiam a produção do conhecimento matemático, considerando o aluno um mero receptor e memorizador de informações, o que Paulo Freire (2005) denominou de Educação Bancária, não produz mais resultados satisfatórios. Acredita-se que isto não é exclusividade de alunos da Educação de Jovens e Adultos. Atualmente, busca-se ensinar e aprender a partir de atividades que propiciem a construção do saber de forma significativa, valorizando os conhecimentos prévios e as vivências dos discentes. Além deste novo paradigma, o qual cada vez mais ganha consenso na comunidade escolar, observa-se a questão do analfabetismo digital, uma preocupação da sociedade contemporânea que vive imersa em Tecnologias Digitais (TDs). Hoje, não basta apenas saber ler e escrever na língua materna. É necessário que se saiba navegar no ciberespaço, criado a partir da Internet, e utilizar seus recursos. Este novo cenário muda a perspectiva da formação do aluno, cujas necessidades devem ser consideradas não mais à luz da Sociedade do Conhecimento e sim à da Sociedade da Aprendizagem (Levy, 1996, 1999).

A proposta metodológica desenvolvida nesta pesquisa, apoiada nas idéias de Paulo Freire (Freire, 2005), objetivou auxiliar a compreensão dos conteúdos de Geometria Plana para alunos EJA. Para fazer a ligação entre a pedagogia Freiriana e as concepções colocadas por Levy, desenvolveu-se uma metodologia que inclui a utilização do software de simulação para construção de plantas arquitetônicas, denominado XHOME 3D, e o programa Paint, integrante do ambiente Windows, na organização das atividades com os alunos.

A pesquisa se insere na abordagem naturalístico-construtiva (Moraes, 2002 p. 14), a qual possui características de trabalho qualitativo. $O$ experimento caracteriza-se como um estudo de caso (Lüdke, Andre, 1986), em que se desenvolveu uma proposta metodológica experimental com alunos da VI fase, do Ensino Fundamental, da EJA, na disciplina de Matemática.

\section{2- Caracterização do ambiente e dos sujeitos envolvidos na pesquisa}

A pesquisa foi desenvolvida inicialmente com 65 alunos de duas turmas da VI Fase da EJA (Educação de Jovens e Adultos) do Ensino Fundamental de uma Escola Municipal de Novo Hamburgo. A escola se localiza em um bairro periférico, a $15 \mathrm{~km}$ do centro da cidade, que teve sua origem na década de 80 do século passado, com a desapropriação de terras, objetivando a construção de um loteamento de casas populares. A escola, criada em 1988, é considerada uma referência neste bairro, pois possui turmas desde a educação infantil, passando pelas séries finais do ensino fundamental até a Educação de Jovens e Adultos, abrigando pais e filhos nas suas classes. Possui cerca de 1500 alunos, todos provenientes do loteamento ou das imediações (alunos que residem em áreas de invasão). 
Esse educandário atende na VI fase da EJA, uma clientela de alunos com idade entre 15 e 50 anos. Todos são moradores do bairro em que se encontra a escola, na periferia da cidade, e possuem anseios e interesses heterogêneos. Os alunos com idade inferior a 18 anos, caracterizados Jovens, correspondem a quarenta e seis estudantes (70,3\%); os alunos considerados Adultos correspondem a dezenove estudantes (29,3\%).

Dentre os alunos que participaram desde o princípio dessa pesquisa, pertencem ao sexo feminino vinte e cinco estudantes $(38,4 \%)$ e ao sexo masculino quarenta estudantes $(61,6 \%)$. Desses educandos, quarenta e sete $(72,4 \%)$ trabalham formalmente (com vínculo empregatício) ou informalmente (sem vínculo empregatício) e dezoito $(27,6 \%)$ não estão trabalhando. Aqueles que trabalham desenvolvem atividades profissionais em áreas diversas, como: empresas de construção civil, indústria calçadista, metalúrgicas, comércio varejista, atividades domésticas. Dos estudantes que não estão trabalhando, somente uma aluna está desempregada, pois os demais nunca trabalharam.

A partir do contexto em que os alunos desta escola estão inseridos, da faixa etária a que pertencem, das profissões que exercem, da distribuição por gênero, tem-se o perfil desta comunidade escolar e os objetivos que levaram estes jovens e adultos a retornarem aos bancos escolares. Entre esses objetivos, podemos citar a permanência no emprego, a necessidade de encontrar um emprego melhor, a inserção no mercado de trabalho, para os estudantes que ainda não experenciaram a vida profissional, e o convívio social. Em relação ao contexto em que os alunos estão inseridos, sabe-se que a escola é o único local do bairro que oportuniza atividades diferenciadas de cunho cultural e esportivo, além da sua função educacional. É, também, somente através da escola que estes jovens e adultos têm acesso à informática, o que proporciona a inclusão digital dessa clientela. Além disso, estar nesse ambiente favorece a inclusão social dessas pessoas que, desde cedo, foram excluídas da escola e, da mesma forma, da sociedade. Essa exclusão acaba por lhes imprimir uma baixa auto-estima e um sentimento de autodesvalia. Dessa forma, concorda-se com Fantinato (2004) quando afirma que:

\footnotetext{
"Numa sociedade urbana, letrada, ter sido excluído precocemente da escola não apenas limita o acesso ao mercado de trabalho, como também parece trazer danos de natureza psicológica para o indivíduo nessa situação, levando-o a crer em sua incapacidade pessoal de aprender, que ele transfere para outros setores de sua vida.” (Fantinato, 2004, p. 119).
}

\section{3- Metodologia utilizada na pesquisa}

A pesquisa se insere na abordagem naturalístico-construtiva (Moraes, 2002 p. 14), a qual possui características de trabalho qualitativo, uma vez que busca identificar os conhecimentos que os alunos da VI fase da Modalidade EJA do Ensino Fundamental possuem acerca dos conteúdos de Geometria Plana e de que forma relacionam esses saberes na resolução de situações do seu cotidiano. A partir deste contexto, apresenta-se uma proposta metodológica, por meio de um estudo de caso, para auxiliar alunos da modalidade EJA na compreensão de conteúdos de Geometria Plana, usando o software de simulação de plantas arquitetônicas, denominado XHOME3D, e o programa Paint, 
como elementos articuladores do conteúdo e auxiliares no processo de inclusão digital. Buscou-se também, com essa pesquisa, proporcionar aos professores de alunos EJA uma proposta para ensinar conceitos de Geometria Plana relacionados ao cotidiano dos alunos.

A proposta de investigação utiliza o levantamento de dados quantitativos, feito por meio da análise de coleta inicial, acerca dos conhecimentos prévios dos alunos em relação aos conteúdos de Geometria Plana, e da análise da atividade de coleta final, verificadora das competências desenvolvidas, em relação aos conteúdos de Geometria Plana, após o desenvolvimento da pesquisa com o software simulador. A junção desses dados corrobora para a análise qualitativa do problema em questão, pois se acredita que as categorias quantidade-qualidade não se opõem, mas se inter-relacionam como duas fases do real num movimento cumulativo e transformador, quando se trata de atingir os objetivos do conhecimento de uma realidade complexa que exige o recurso de diferentes abordagens, as quais não só ampliam, mas complementam conhecimentos sobre uma determinada problemática. (Santos Filho, 2002).

No entanto, não se deseja apresentar conclusões fechadas ou generalizar, mas sim levantar indicadores que deles emergirem para compreender a situação. As pesquisas nesta abordagem não têm pretensões de generalização estatística, mas a compreensão dos fenômenos estudados. (Moraes, 2002, p. 15).

\section{4-Atividades desenvolvidas com os alunos}

Nesta escola, os alunos têm o hábito de frequentar o Laboratório de Informática semanalmente, pois essas aulas fazem parte do currículo escolar e precisam ser desenvolvidas por diferentes professores, em diferentes disciplinas, no decorrer do ano letivo. O trabalho no Laboratório é desenvolvido por meio de projetos, em que os alunos, orientados pelos professores, constroem sua própria aprendizagem. Partindo dessa premissa e da dificuldade que os alunos possuem em relacionar o conteúdo matemático desenvolvido na escola com sua aplicação no seu cotidiano, foi desenvolvida uma proposta metodológica, de cunho transdisciplinar, para auxiliar na compreensão de conteúdos de Geometria Plana, para alunos da Modalidade EJA. Essa proposta baseia-se na utilização de softwares de apoio, que funcionam como elementos articuladores do conteúdo e, também, auxiliam no processo de Inclusão Digital desses educandos.

O trabalho foi estruturado em quatro etapas, distribuídas ao longo do primeiro trimestre letivo de 2009, e teve a participação efetiva de 46 alunos (número de alunos que participaram de todas as etapas do experimento).

A primeira etapa consistiu da atividade de Sondagem com exercícios contextualizados de Geometria Plana, envolvendo retas paralelas, retas perpendiculares, perímetro e área de polígonos. Essa etapa teve como objetivo verificar os conhecimentos prévios que estes alunos possuíam acerca deste conteúdo e de que forma relacionavam o conhecimento matemático formal com a Matemática que utilizam diariamente no seu cotidiano. Posteriormente foi feita uma retomada das questões propostas na Sondagem com o objetivo de construir os conceitos de Geometria Plana que não eram do conhecimento da maioria dos estudantes. Nessa nova visada sobre o assunto, foram utilizados os conhecimentos prévios relacionados com a aplicabilidade no seu cotidiano. "A busca de uma possível integração dos conhecimentos matemáticos escolares com os do cotidiano não pode ser um pretexto para a desvalorização do conhecimento primeiro do educando.” (Fantinato, 2004, p. 122). 
$\mathrm{Na}$ segunda etapa, usando o software Paint, foram realizadas atividades de reconhecimento de figuras geométricas planas, de polígonos, de área e perímetro, de retas paralelas e perpendiculares. No Laboratório de Informática da escola, os alunos aprenderam a manipular o software gráfico e suas ferramentas, onde desenharam a Planta Baixa da sala de aula e realizaram atividades de Geometria Plana. Posteriormente, realizaram atividades contextualizadas de Geometria Plana, utilizando o mapa do bairro, onde se localiza a escola, e outros exercícios de fixação, pertinentes ao tema proposto. A atividade de construção da planta baixa da sala de aula pode ser visualizada na Figura 1.

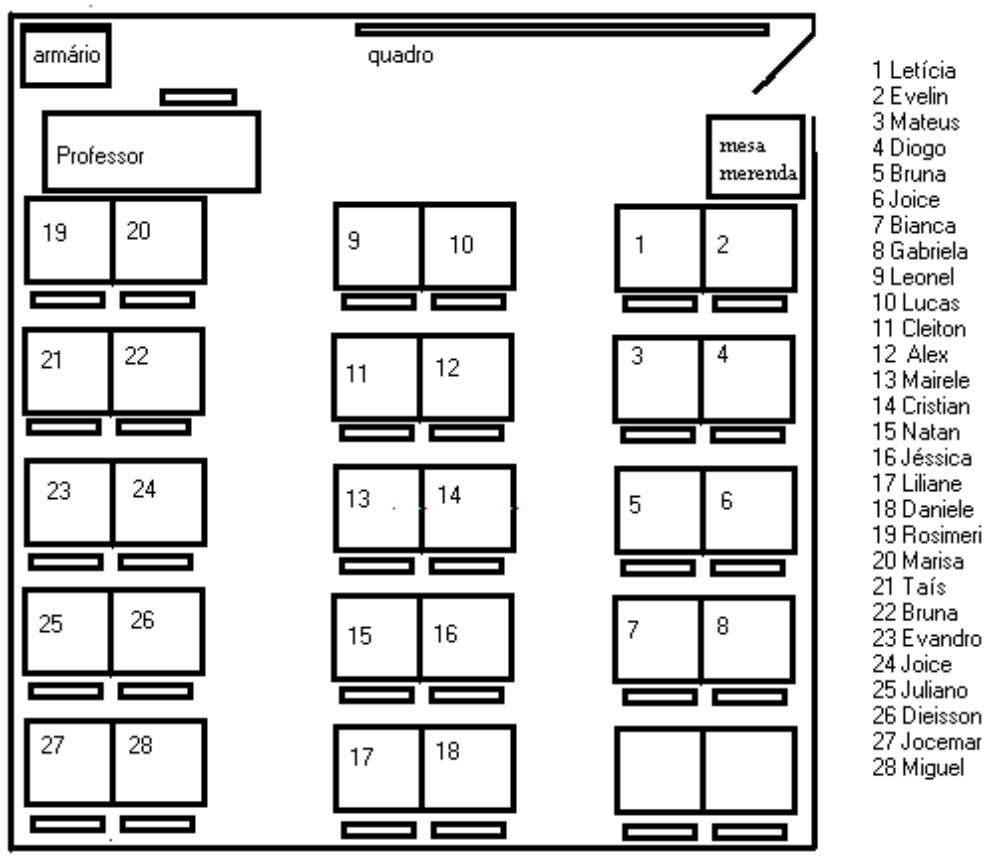

Figura 1- Planta baixa da sala de aula

Na terceira etapa os alunos aprenderam a manipular o software simulador de plantas arquitetônicas XHOME3D, onde desenharam a Planta Baixa da escola. Depois disso, construíram a maquete da escola com material reciclado, que teve seu modelo em 3D visualizado no simulador. Esta situação ilustra a afirmação de Rios (2005) “... o uso e a apropriação das tecnologias da comunicação e informação na escola sejam vistos como forma de inclusão social e construção de conhecimento.” (p. 68). A interface do software XHOME3D, a planta baixa da escola e a maquete da escola podem ser visualizadas nas Figuras 2,3 e 4. 


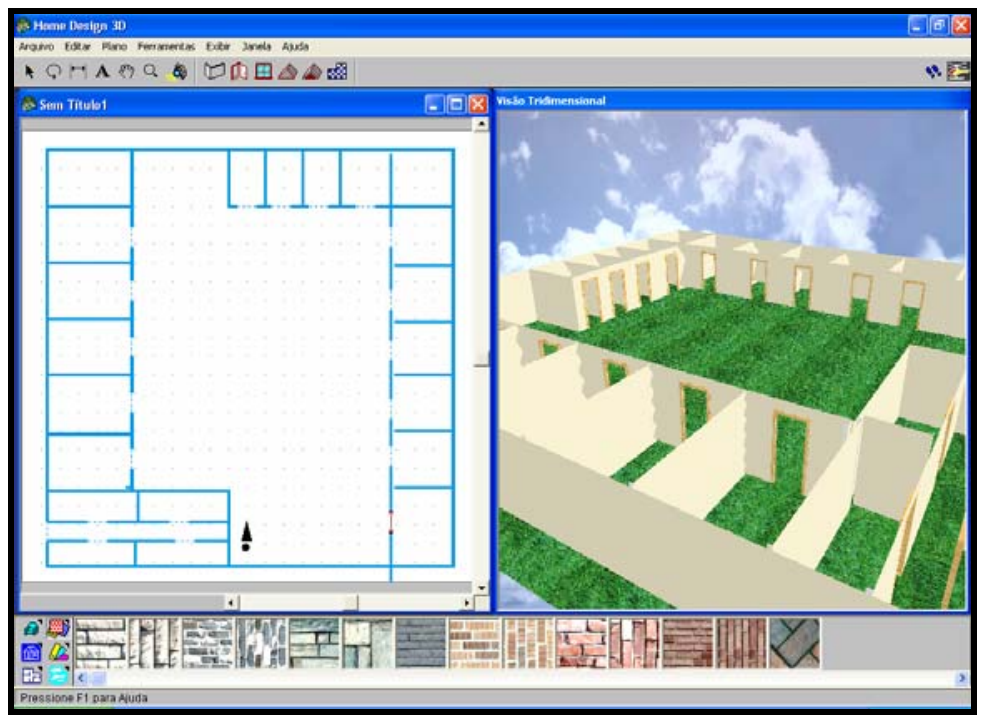

Figura 2 - Planta baixa da escola em 3D

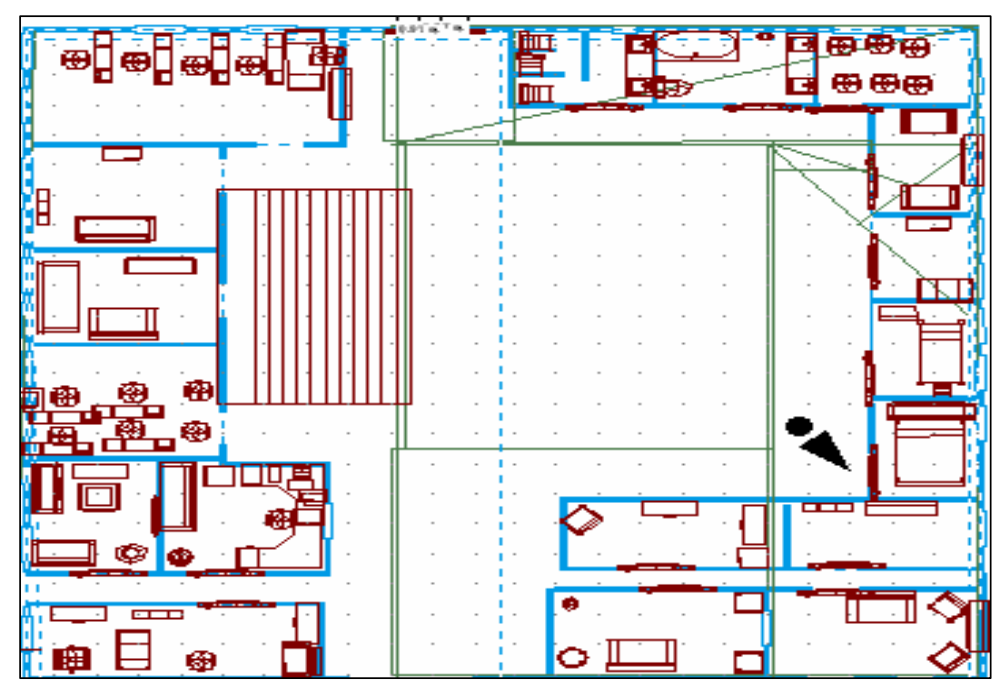

Figura 3- Planta baixa da escola

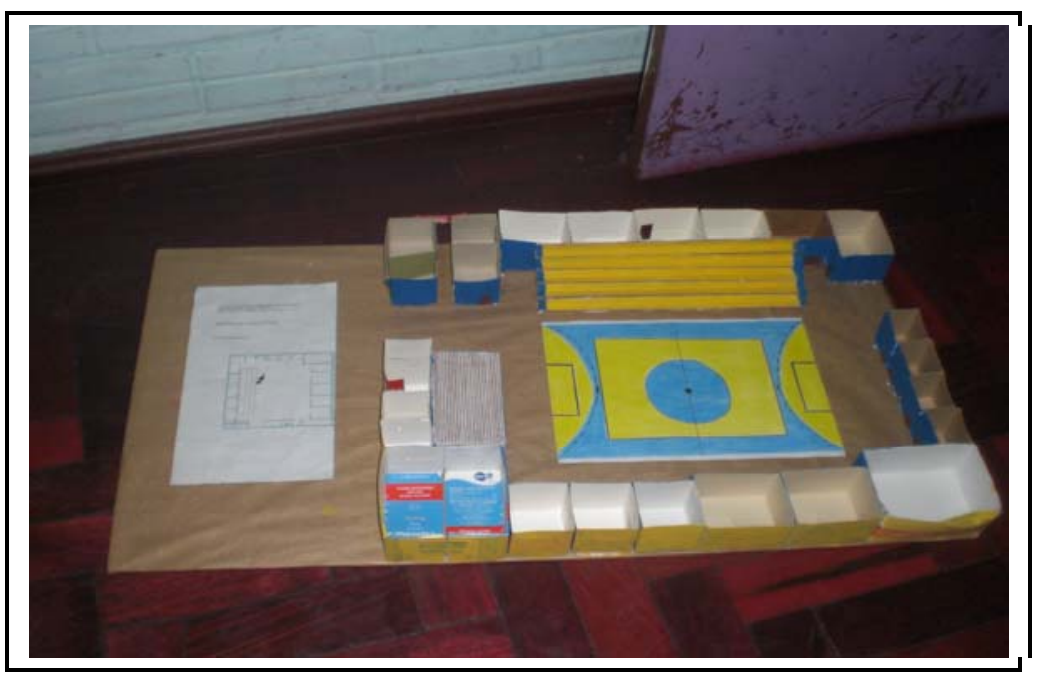

Figura 4- Maquete da escola construída com material reciclado 
Após a conclusão do projeto com o software, efetuou-se a última etapa da pesquisa que consistiu na aplicação de um instrumento verificador das competências desenvolvidas pelos alunos em relação aos conteúdos de Geometria Plana. Esta atividade foi composta de exercícios contextualizados de Geometria Plana com conteúdo semelhante ao pré-teste.

A proposta metodológica foi colocada em prática utilizando três períodos semanais de aula, com 45 minutos cada, durante os meses de Abril, Maio e Junho de 2009. As atividades de laboratório totalizaram 20 horas e foram realizadas de forma distribuída, considerando o trabalho realizado em sala de aula presencial e posterior atividade prática.

\section{5- Resultados e discussões}

O grupo, composto por quarenta e seis alunos, resolveu, em duplas, sem o auxílio ou explicação da professora, uma atividade de Sondagem, contendo exercícios escritos que retratavam o cotidiano e que estavam relacionados ao conteúdo de Geometria Plana (retas paralelas, retas perpendiculares, perímetro, área). Essa atividade foi aplicada com o intuito tanto de verificar os conhecimentos prévios que estes estudantes tinham a respeito deste objeto matemático como de perceber de que forma estabeleciam analogia desse conhecimento matemático com situações do seu dia a dia. Após esta atividade, foi realizada a correção dos exercícios, em que se verificou que quarenta e dois alunos $(91,3 \%)$ conseguiram resolver menos da metade dos exercícios propostos e quatro alunos (8,7\%) resolveram a metade dos exercícios propostos.

Em seguida a esta etapa, foram realizadas, no Laboratório de Informática da escola, atividades de construção do conhecimento matemático de Geometria Plana, associadas a situações do cotidiano, através do programa Paint e do programa simulador XHOME3D, que funcionam como elementos articuladores do conteúdo e promovem a Inclusão Digital. Além disso, foram trabalhados exercícios escritos, envolvendo situações matemáticas contextualizadas à realidade dos alunos, culminando com a construção da maquete da escola com material reciclado, que teve seu modelo construído e visualizado em 3D no simulador XHOME3D.

A partir dos exercícios realizados na sala de aula e no Laboratório de Informática, associados à proposta metodológica, foi possível observar a quebra de resistência e o entendimento dos conteúdos e, principalmente, a associação do estudado ao seu cotidiano. Certamente, a percepção do crescimento dos alunos no que tange ao conhecimento e vinculação do aprendido ao seu dia a dia foi realmente estimulante para a pesquisadora.

Como atividade de coleta final dos dados, a fim de verificar as competências desenvolvidas em relação aos conteúdos de Geometria Plana, com uso do software simulador, foram utilizados exercícios escritos, semelhantes àqueles propostos na Sondagem. A atividade foi resolvida por quarenta e seis alunos, na sala de aula, observando-se que, após a correção da tarefa, trinta e quatro alunos $(73,9 \%)$ resolveram mais da metade dos exercícios propostos e doze alunos $(26,1 \%)$ resolveram a metade ou menos da metade dos exercícios propostos. 


\section{6- Conclusões}

Os dados obtidos no levantamento realizado na sondagem, através da resolução de situações-problema, contextualizadas à realidade dos sujeitos, demonstraram que os alunos participantes desta pesquisa não faziam associação entre o conhecimento matemático formal com a Matemática utilizada para resolver situações do seu cotidiano. Acredita-se que isto não se deve somente às lacunas do ensino de Matemática ou da dissociação deste com situações cotidianas, mas também a dificuldade que os alunos possuem em ler e interpretar qualquer enunciado de exercícios ou situações-problema.

Os estudantes da EJA, principalmente os jovens, são remanescentes de um processo de sucessivas reprovações que culminaram com o abandono escolar. Possuem, assim, muitas falhas de leitura e de escrita. Além disso, não tinham o hábito de resolver exercícios matemáticos em que necessitassem destas competências. Apenas resolviam exercícios com algoritmos, equações, nos quais eram demonstradas as resoluções por meio de vários exemplos e, posteriormente, aplicavam estes mecanismos na resolução, como um treinamento. Dessa forma, este pode ser um dos aspectos que justificam a dificuldade que possuíram na resolução destas atividades.

Os trabalhos desenvolvidos em grupos, que foram as atividades com os softwares e a construção da maquete, propiciaram uma aproximação entre os jovens e os adultos, que se ajudaram, compartilhando os saberes, deixando de lado a antiga rixa entre as diversas faixas etárias. As atividades escritas, realizadas em dupla ou individualmente, propiciaram, após a construção e reconstrução dos saberes matemáticos por meio da valorização dos conhecimentos prévios, momentos de reflexão, troca de informações e organização do pensamento. Especialmente por proporcionarem a apropriação do conhecimento matemático formal associado a situações do cotidiano, promovendo a interação entre a Matemática da escola e a Matemática da vida.

$\mathrm{Na}$ última etapa do trabalho, quando foram aplicados os exercícios verificadores das competências desenvolvidas durante o experimento, e foram comparadas as respostas com os dados obtidos na sondagem, pode-se verificar um expressivo crescimento dos alunos em relação à construção e apropriação do conhecimento matemático. A partir da análise dos dados, pode-se verificar um aumento de $88 \%$ no número de questões certas, comparado com os números obtidos na sondagem, no início do experimento, demonstrando um crescimento significativo. Acredita-se que as experiências foram significativas e o desenvolvimento das atividades demonstra dados expressivos, após a aplicação do experimento.

\section{Referências Bibliográficas}

FANTINATO, Maria Cecília de Castello Branco. A construção de saberes matemáticos entre jovens e adultos do Morro de São Carlos. Revista Brasileira de Educação, n.27, p. 109-124, set/out/nov/dez., 2004.

FREIRE, Paulo. Pedagogia do Oprimido. 44. ed. São Paulo: Paz e Terra, 2005. 213 p.

LÉVY, Pierre. Cibercultura. São Paulo: Editora 34, 1999. 250 p.

O que é Virtual? São Paulo: Editora 34, 1996.110p. 
LÜDKE, Menga; ANDRE, Marli E.A. Pesquisa em Educação: abordagens Qualitativas. São Paulo: EPU, 1986.

MORAES, Roque; GALIAZZI, Mario do Carmo. Análise Textual Discursiva. Ijuí: Unijuí, 2007, 224 p.

RIOS, Clara Maria Almeida. Tecnologias em Educação de Jovens e Adultos em Busca de Novas Proposições. Educação e Contemporaneidade, Salvador, v. 14, n. 23, p. 6372, jan./jun. 2005.

SANTOS FILHO, José Camilo dos. Pesquisa quantitativa versus pesquisa qualitativa: o desafio paradigmático. In: SANTOS FILHO, José Camilo dos; GAMBOA, Silvio

Sánchez (org.). Pesquisa Educacional: quantidade-qualidade. São Paulo: Cortez, 2002. p. 13-59. 